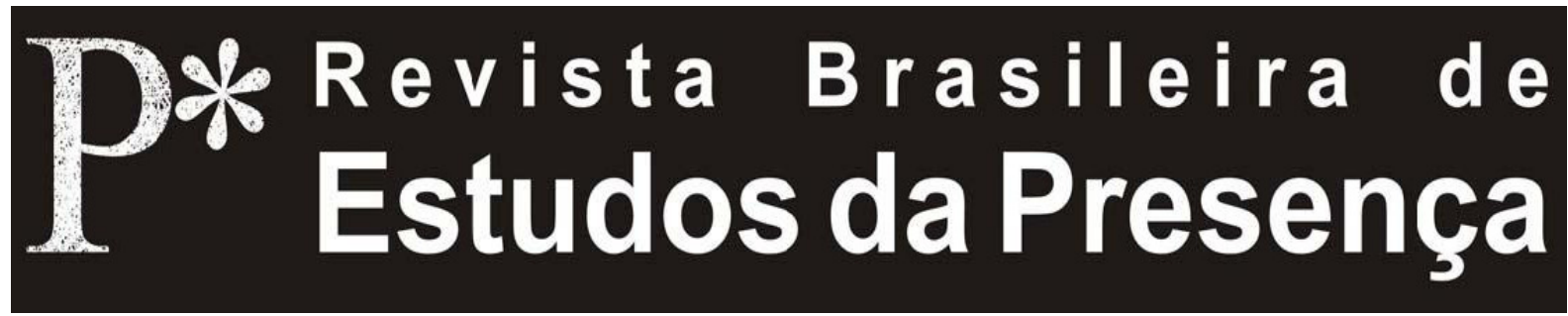

DOI - http://dx.doi.org/10.1590/2237-266039254

ISSN 2237-2660

\title{
Intervenciones en el Espacio Público: performance, mirada y ciudad
}

\author{
María Laura González \\ Universidad de Buenos Aires - UBA, Buenos Aires, Argentina
}

RESUMEN - Intervenciones en el Espacio Público: performance, mirada y ciudad - El artículo parte de la paradoja teatral: ser o no ser en la escena. Pero ¿qué ocurre cuando ésta sucede dentro de un ámbito de la vida cotidiana? Los ciudadanos se vuelven parte de ella y se convierten, a la vez, en espectadores activos que deben reconocer momentáneamente, la instancia de relato ficcional. Este tipo de teatralidad propone cambiar la mirada habitual sobre la ciudad y mezclar los roles entre quienes miran y quienes son mirados, como un juego de presencias. Para analizar esta cuestión tomaremos la performance urbana de Mariano Pensotti, A veces creo que te veo realizada en 2010.

Palabras-clave: Performance. Ciudad. Mirada. Espacio Público. Intervención.

ABSTRACT - Interventions in the Public Space: performance, gaze, and the city This article is based on the following assumption: to be or not to be on the stage. However, if the stage is real life, part of a public space, this situation is a very complex one. Thus, everyday urban life becomes an artistic and performance event. In this way, citizens become active spectators. Urban interventions change the usual way of regarding the city, and propose a blurs the line between the roles of the person who looks and the person who acts. The example to discuss this game of presences will be $A$ veces creo que te veo (Sometimes I think I can see you), a performance work done in Buenos Aires by Mariano Pensotti, in 2010.

Keywords: Urban Performance. City. Gaze. Public Space. Intervention.

RÉSUMÉ - Interventions dans l'Espace Public: performance, regard et ville - Cet article a pour point de départ le paradoxe théâtral: être ou ne pas être sur scène. Mais que se passe-t-il lorsque cette dernière intervient dans le cadre de la vie quotidienne? Les citoyens deviennent alors des spectateurs actifs devant reconnaître, momentanément, la scène comme un récit fictionnel. Ces interventions urbaines changent le regard habituel sur la ville et proposent une inversion des rôles entre regardants et regardés, dans un jeu de présences. Pour réfléchir sur cette question, nous prendrons l'exemple de la performance urbaine $A$ veces creo que te veo (Parfois je crois que je te vois) réalisée par Mariano Pensotti en 2010. Mots-clés: Performance. Ville. Regard. Espace Public. Intervention. 


\section{A Modo de Introducción}

Partiremos de una paradoja eminentemente teatral, la de ser/ estar (o no) en escena. Su conceptualización no compete únicamente a la presencia corporal del actor, sino también a la posibilidad de generar con ella un proceso comunicacional variable entre quienes observan y quienes son mirados. Decodificar, esa es la cuestión. Sin embargo, cuando el escenario elegido para accionar es el espacio público la problemática se complejiza. Porque tanto los performers - dispuestos a participar y provocar el acontecimiento -, como los urbanitas - quienes en el mismo momento de la intervención se encuentran transitando ese lugar - se vuelven parte de la escena misma. Estos últimos deben repentinamente identificar lo que ocurre como una instancia ficcional. Al ser parte de ese dispositivo teatral interventor, su mirada necesita reacomodarse, asistiendo a un desdibujamiento de los límites entre realidad y ficción que oscila entre el mirar y el ser mirado. La teatralidad que irrumpe lo cotidiano modifica el anonimato habitual, tensiona lo público con lo privado y propone un juego de presencias alternas.

Las siguientes líneas pretenden ser una reflexión acerca de las presencias instantáneas que se actualizan en una performance urbana. La pregunta será si puede un acto efímero realizado en un espacio público cotidiano generar otros modos (perdurables) de mirar la ciudad. Sin resolver la cuestión, sino simplemente permitirnos deliberar sobre ella, el recorrido dispuesto desembocará en la mención de un caso concreto de intervención urbana como fue $A$ veces creo que te veo, dirigida por Mariano Pensotti, que tuvo lugar en una estación de tren de Buenos Aires en 2010 dentro del marco del Festival Ciudades paralelas ${ }^{1}$.

\section{Yuxtaposición de Presencias}

A mediados del siglo XX, la ciudad comenzó a ser pensada como una construcción social que, además de presentarse como una materialidad arquitectónica, se constituye a partir de diversas maneras de ser, mirar y practicar sus espacios por parte de quienes la habitan, es decir, los urbanitas. Estos convierten a la vía pública en una gramática y una geografía imaginaria a partir de su tránsito, como así también poetizan la trama ciudadana al desplegar una sucesión diacrónica 
de puntos en el espacio (Delgado, 2007, p. 71). Los sujetos urbanos habitan colectivamente el espacio público, entendido como aquel que

[...] acepta la heterogeneidad y la posibilidad de la copresencia con los 'otros' a condición de someterse a ciertas reglas, a un 'orden' que implica una visión dominante de los 'modos legítimos de uso' y el disciplinamiento del público con base en dichas reglas. [Proceso que] ha sido denominado 'domesticación de la calle' (Balwin apud Duhau, 2004, p. 173).

Allí las identidades de los sujetos adquieren un carácter fronterizo, de superficie, particularmente situado en los rostros. La distracción, la hipertrofia del ojo y una sensación de embotamiento cuasi sonámbula para el andar son maneras de ser y de atravesar este espacio (Joseph, 1988). El paseante urbano se muestra "incapaz de desenmascarar o de interpretar [...] se baña en la muchedumbre, se baña entre sus semejantes" (1988, p. 50-51). Entonces, al ser parte de esa multitud se mimetiza colectivamente con ella dentro de ese "marco puramente acontecimiental" (Delgado, 2007, p. 50). Es ahí donde la socialización y la resocialización interpersonal se negocian permanentemente.

Por otro lado, el espacio urbano "[...] no es un lugar, sino un tener lugar de los cuerpos que lo ocupan en extensión, y en tiempo" (Delgado, 2007, p. 13). Cotidianamente, organiza un orden social que es conformado por conductas cuasi-predecibles. Por ello, son los sujetos los que hacen de la ciudad un lugar practicado y habitado de constante fluctuación y movimiento y donde el puro acontecimiento los conecta con la arquitectura circundante que transitan a diario como escenario.

En suma, se puede decir que la relación entre el sujeto con su espacio público se estructura suturando cualquier tipo de intervalo o distancia que pueda suceder respecto del orden esperable. Allí es donde se pierde el sentido del mundo, el sentido crítico, para lograr refugiarse detrás de parámetros reconocidos colectiva y socialmente por todos. Parecería ser que en este espacio urbano nada es predecible $y$, al mismo tiempo, todo se supone en un ordenamiento esperable, homogéneo.

Sin embargo, esta polifonía del espacio público en las ciudades actuales también permite un margen para lo extracotidiano. Como ciudades abiertas (Sennet, 2007), éstas dan lugar a formas incompletas y hacen del urbanismo una experiencia más democrática de la 
ciudad (Pitrola, 2010-2011, s/p); por lo que no todo parece predecible o acabado. Tal es el caso de las coaliciones peatonales (Delgado, 2007, p. 153): fiestas, procesiones, manifestaciones, reclamos sociales, carnavales o intervenciones que también tienen lugar dentro del espacio público, al utilizarlo como su escenario de acción. Estos acontecimientos no esperables - especie de arritmia de lo cotidiano - alteran el anonimato de los sujetos y el sentido lexicalizado o naturalizado que se tiene incorporado acerca de ese lugar. Sobre estas acciones imprevistas, particularmente las de índole artística, queremos indagar. Es decir, indagar en torno de aquella teatralidad que aparece donde no se esperaba que apareciera, permitiendo así focalizar/recortar la visión sobre un detalle específico del paisaje urbano.

Cuando el acto de arte público irrumpe, la teatralidad se hace presente visiblemente, dejando ausente las reglas básicas de ese andar, para instalar una dualidad espacio-temporal paradójica entre lo real y lo ficcional momentáneo. Pero, ¿en qué tipo de intervención teatral dentro del espacio urbano estamos pensando?

Si bien las intervenciones urbanas pueden variar según las ciudades y los contextos socio-políticos atravesados, la adopción de esta modalidad específica responde - directa o indirectamente - a un orden hegemónico con el que dialoga, se contrapone, rechaza o bien, aplica sus resistencias. La acción de tomar la calle desde la práctica artística se vuelve eminentemente política, nunca es involuntaria. Evidentemente, encontrarse bajo una coyuntura socio-política de dictadura no es igual que accionar dentro de circunstancias democráticas; como así tampoco que la acción se realice en una ciudad cosmopolita, o dentro de una localidad interina menos urbanizada. Esto significa que el contexto socio-cultural resulta determinante para la realización y recepción de la obra de arte público. La intervención se inserta dentro de un ámbito regido por conductas y hábitos predeterminados y su recepción variará según ese marco contextual y los modos de percepción puestos en relación.

Al buscar ejemplos que utilizaron a la ciudad como soporte escenográfico aparece una heterogeneidad de propuestas disímiles. Por un lado, se encuentran aquellas prácticas teatrales callejeras más convencionales que, desde el Medioevo, llevan su arte a las plazas o calles de la ciudad. Estas manifestaciones artísticas suelen anticipar o anunciar la teatralidad por acontecer, convocando al transeúnte como un espectador casual - a formar parte de una ronda y del desar- 
rollo de una trama. Pero, por otro lado, aparecen prácticas artísticas que varían en procedimientos y proponen con su intervención reflexionar no sólo sobre el propio lenguaje, sino también sobre el espacio intervenido. Este tipo de intervención urbana, que desde las últimas décadas viene dialogando con su contexto propone una relectura sobre lo urbano y una tensión al resquebrajar la realidad cotidiana, propone sorprender al transeúnte dislocándolo instantáneamente como parte de una ficción imprevista. Suelen ser interdisciplinarias, generando escenas en diálogo con otras artes, como las plásticas, las tecnológicas o las musicales, entre otras. Situados en la ciudad de Buenos Aires, durante las últimas décadas, algunos ejemplos de este tipo de intervención podrían ser: El Siluetazo (Buenos Aires, 1983); las performances iniciales de La Organización Negra (Buenos Aires, 1984); el proyecto Filoctetes (por Emilio García Wehbi, Buenos Aires, 2003); Mayo, los sonidos de la plaza (por Buenos Aires Sonora, 2003 y 2007); Pizurno Pixelado (por Margarita Bali, dentro del FIBA, 2005); o bien las obras de Mariano Pensotti realizadas en diversas ocasiones desde 2005 en adelante.

Estas intervenciones urbanas consistieron en utilizar el espacio público a partir de dibujar sobre papel la silueta - a escala humana de los 30.000 desaparecidos de la última dictadura militar, reclamando la aparición con vida y justicia (aún en dictadura); interrumpir el tiempo de espera de un semáforo con un simulacro de fusilamiento de ocho personas vestidas de civil (apenas recuperada la democracia); colocar en veredas muñecos híper-realistas cuyos cuerpos manifestaban una indigencia extrema que apelaba a la solidaridad de los demás transeúntes que pasaban a su lado; sonorizar la Plaza de Mayo con la reproducción auditiva de discursos históricos paradigmáticos acontecidos en dicho lugar después del 2001; proyectar videos sobre la fachada del Palacio Pizzurno; recrear en las ventanas, vidrieras y vereda de un pasaje de la ciudad (Rivarola) escenas de la vida cotidiana, mediante la proyección de pensamientos de sus protagonistas. Y si “[...] toda operación artística implica una operación consciente o inconsciente de desciframiento" (Bourdieu, 2002, p. 61) entonces, el contexto urbano elegido colaboró o no para la decodificación de cada una de estas obras que apelaron a redefinir la mirada sobre la ciudad.

Es la ciudad la que permite una sobredeterminación de acciones esperables, pero, también, admite la posibilidad de lo accidental, aún cuando esto se intente salvaguardar (desde la apariencia) para 
conservar la estructura social cotidiana (Joseph, 1988). Los ejemplos arriba mencionados, como coaliciones, incidieron directamente sobre esa estructura social, para mostrar sus pliegues y para despertar la mirada acostumbrada. Lo relacional, entonces, es parte de lo estéticoartístico (Bourriaud, 2008) de cada intervención. Relacional porque buscaron posibilitar un diálogo con su ciudad.

\section{A veces creo que te veo/Estación ${ }^{2}$}

Una estación de trenes. Cuatro escritores observan el lugar desde diferentes puntos de vista. En sus computadoras portátiles escriben en vivo lo que ven en la estación. Y también escriben sobre otras cosas, a veces personales, a veces inventadas, a veces históricas. Todo lo que van escribiendo se proyecta en pantallas de video. Los espectadores y los transeúntes ocasionales de la estación de trenes comienzan a ser parte de la narración de los escritores.

Cuando miran las pantallas notan que se están convirtiendo en personajes de una ficción escrita en el momento. Los espectadores ven cómo los escritores crean una suerte de novela en vivo tomando la realidad específica que los rodea. Y a la vez tienen la posibilidad de 'actuar', interferir esa ficción; son parte de la creación colectiva de una narración que refleja un tiempo y un espacio. A la manera de una cámara de seguridad que registra todos los movimientos de personas anónimas en el espacio público, cada escritor crea narraciones instantáneas que reflejan lo que ve o imagina acerca de la gente y las posibles historias escondidas en ese lugar de paso (Pensotti, 2010, s/p) ${ }^{3}$.

Nos detenemos en una performance urbana puntual: $A$ veces creo que te veo de Mariano Pensotti. En ella se observan algunas características estéticas y procedimentales, tales como la mirada dialéctica en los transeúntes, la hibridez de planos propuestos - entre lo real y lo ficcional - y la desnaturalización del sentido cotidiano de ese espacio público, la estación. Desarrollada dentro del marco de un festival que se propuso pensar formas de relacionar lo público con lo privado, esta intervención apuntó a una conversión de transeúntes en espectadores y performers.

Al poner en relación el mundo ordinario con el de la ficción/ narración, puede pensarse como obra artística relacional, ya que conceptualmente instaló un diálogo entre ambos. Así, al conjugarlos variablemente dentro de la propia intervención/escena, el foco estuvo puesto sobre el espectador, quien resultó un eslabón fundamental 
para la constitución de la obra. Es decir, no sólo se lo pensó como consumidor, sino también como participante productor de sentido. Según Nicolás Bourriaud:

La intersubjetividad, en el marco de una teoría 'relacionista' del arte, no representa solamente el marco social de la recepción del arte, que constituye su 'campo' (Bourdieu), sino que se convierte en la esencia de la práctica artística [...] producir una forma es inventar encuentros posibles, es crear las condiciones de un intercambio (Bourriaud, 2008, p. 23-24).

En este caso, la forma de la intervención es la que dialogó y puso en relación a dos sujetos (al creador y al espectador). Por su parte, una de las curadoras del festival, Lola Arias, declaró que se trató de:

[...] un festival de teatro sin actores. El espectador actúa en todo el sentido de la palabra. El espectador debe realizar una acción para tener una experiencia que hace que la obra exista. Si el espectador no actúa, no hay obra [...] si no se deja describir por los escritores de la estación [...] la obra no existe. En este tipo de trabajos, ¿se puede seguir hablando de espectador? ¿Cómo llamar esa nueva posición? ¿Participante, experimentador, viajero, descubridor, protagonista? Los proyectos [del festival] transforman el espacio público de una forma muy distinta (Pitrola, 2010-2011, s/p).

La intervención de Pensotti, entonces, se iniciaba cuando los escritores/actores tomaban a un sujeto en particular y empezaban a imaginar algún aspecto de su vida. Comenzaban entonces a escribir esas ideas. El relato construido sobre la marcha era proyectado en cada pantalla. A partir de esta acción inicial, el juego con los espectadores-performers-narradores-transeúntes comenzaba a mutar según el registro o no de lo acontecido, como así también a partir de la inclusión o no de sus propios cuerpos como soportes del relato de las historias narradas.

Como en La Marea (2005-2010), Pensotti volvió a intervenir el espacio público de Buenos Aires conformando una dramaturgia de lo cotidiano creada a partir de la utilización de un espacio urbano real - en el horario de su tránsito habitual - y donde el pensamiento de los personajes/performers fue proyectado por escrito, permitiendo su visualización. Así, la estación de trenes Palermo de la línea San Martín dejó de ser un no-lugar - en términos de Marc Augé (2005) - para convertirse en un lugar practicado - en términos de Michel De Certeau (2007) - compuesto de subjetividades narradas. 
Por su parte, el sujeto ciudadano que llegó a tomar el tren pudo haber observado que en el espacio había algunos elementos extracotidianos - la instalación de las pantallas - que anticipaban la emergencia de una coalición dentro del continuum habitual, sin saber exactamente en qué consistiría. Así, una vez iniciada la acción, hubo tres casos posibles de espectadores-participantes.

El primero sería el de los urbanitas que leyeron las pantallas y se dieron cuenta que algo de lo que aparecía como texto escrito podría estar basado en su persona (aspecto físico; colores de su vestuario; corte de pelo; bolso o equipaje; compañía etc.). Esto los habría convertido en espectadores/lectores duales, ya que también resultaron ser los protagonistas del relato. En este sentido, Lola Arias opina que los que fueron a tomar el tren y no fueron allí por la obra, quedaron atrapados por la obra y se convirtieron en protagonistas efímeros de la novela que escribían en vivo los escritores (Pitrola, 2010-2011). Sin embargo, entre éstos urbanitas protagonistas pudo haber una diferencia sustancial: entre quienes registraron el juego propuesto - y modificaron el curso de la historia narrada realizando algún gesto, alguna acción que el narrador tomase para modificar lo que venía escribiendo (es decir, performers activos de la escena) - y quienes no accionaron a pesar de saberse parte de la acción (es decir, performers pasivos).

Por otro lado, un segundo caso posible sería el de aquellos que fueron tomados como personajes inspiradores de las historias del narrador, pero que no lograron darse cuenta de lo sucedido, ni llegaron a leer nada de lo escrito y, entonces, fueron parte del evento sin siquiera haberse enterado. Estos serían los performers elegidos que no alcanzaron a convertirse en espectadores.

Mientras que un tercer caso sería el de aquellos que no fueron objeto de inspiración para el escritor, pero que sí leyeron las pantallas y localizaron sobre quién se escribía, estableciendo una correlación entre el transeúnte real y el personaje ficcional.

Entonces, a medida que la acción avanzaba, los roles de mirar y de ser mirado se modificaban. Unos podían ser los protagonistas momentáneos y, luego, otros y, luego, otros más. Inclusive, podía resultarles interesante leer qué se escribía sobre ellos, qué ficción les adjudicaban a partir de los pensamientos, qué biografía se inventaba. Por ejemplo, uno de los cuatro escritores de la intervención escribió lo siguiente: 
En el año 2013 no habrá nada...no habrá estación... dos chicas están frente a la pantalla y leen...

Me gusta el color de sus ropas.

Una viste un sweater rojo y naranja con flores. Le envidio ese sweater.

Y la otra de verde, un verde peculiar, no cualquier verde.

Estudian Letras.

Juntas.

Se pasan todo el día juntas

como hermanas ${ }^{4}$

Mientras esto sucedía, una cámara provista para la ocasión registraba el desarrollo de la intervención. En ese archivo audiovisual ${ }^{5}$, se puede observar a las dos chicas darse cuenta de lo sucedido, y con empatía, reírse de lo que estaban leyendo. Ellas serían parte del caso número uno, de los que fueron performers y espectadores/lectores a la vez; y que con su aprobación o empatía - respecto del relato - lo disfrutaron sin tener que intervenir en el curso de la acción.

Otro de los escritores se detuvo en dos chicas que esperaban la llegada del tren tomando mate, sobre las cuales enunció lo siguiente:

Por 20 días voy a ser brasilera. Voy a exprimir Brasil-piensa.

Ya falta poco

Mientras se va el tren

Ya imagina a su avión despegando

Ahora toman mates sonrientes

Quiere cambiar de tema para no quemarlo ${ }^{6}$

Ambas chicas se encontraban debajo de una de las pantallas. Sólo una atinó a leer lo escrito, mientras que la otra pareció no darle importancia.

En definitiva, cada narrador, cual prestidigitador, observó el panorama que tenía delante de sí y, resaltando y extrayendo algo todo aquello, lo convirtió en otra cosa. Es decir, lo volvió parte de su relato/escena. Con ello reinventaba lo cotidiano como instancia ficcional. Como constructores de la trama necesitaron de la colaboración de esos otros cuerpos habitantes del lugar, como fuentes de su inspiración. Miraban sin ser vistos, a modo de efecto visera (Derrida, 1995, p. 21), al vigilar los movimientos de los transeúntes. Entonces, un gesto, un modo, un hábito observado les bastó para incorporarlo a la escena y narrarlo como parte de la descripción de pensamientos.

A partir de esta estructura, la situación cobró un carácter movedizo, liminal (Diéguez Caballero, 2007). Un espacio que dejó de ser 
cotidiano para pasar a ser un escenario repentino de lo espectacular. Escenario de un soporte de lectura (pantallas mediadoras) donde el texto se gestaba como construcción procesual. Así, ambas instancias, la productiva (acción) y la receptiva (lectura) convivieron en la misma estación por un breve lapso. De esta manera, Pensotti relacionó la lectura con la participación, con la percepción, con la acción y con la escritura, dentro de un espacio que supo resignificarse a partir de quienes participaron con percepción activa. En otras palabras, y coincidiendo con Lola Arias, habría sido necesaria la decodificación del suceso como un evento extracotidiano para la concepción de la obra.

El evento, entonces, propuso un diálogo entre los sujetos que a diario comparten un espacio como cotidiano, pero que no acostumbran a mirar y a mirarse en detalle, en sus formas. Pensotti pensó en un juego de miradas/presencias/relatos efímeros capaces de materializar - como constelación ficcional - un espacio-tiempo otro preciso sobre el de orden cotidiano. Porque si tal como sostiene Antony Muntadas (2007), la percepción requiere participación, entonces, haber percibido este suceso como una coalición extacotidiana requirió de una atención diferente, activa. Participar, ser parte de, compartir, con la intención de animarse al juego de lo ficcional, dejando atrás - por unos instantes - la hipertrofia del ojo acostumbrado a lo masivo, a lo general, a lo fuera de foco.

Por otro lado, y como dijimos, esta intervención fue realizada dentro del marco de un festival que, además, se encargó de registrar lo ocurrido como así también de la promoción y difusión previa (vía Internet y otros medios) sobre su programación. A partir de esto, algunos de los espectadores de la intervención no habrían sido transeúntes casuales, sino que habrían asistido especialmente a la estación por inquietud, al estar enterados de la propuesta. Es decir, que sumados a los tres casos anteriormente enunciados, habría una cuarta instancia espectatorial: la de aquellos que concurrieron intencionalmente para ver de qué se trataba. E inclusive, alguno de estos pudo haberse convertido en un performer inspirador y soporte de los relatos narrados.

Los registros audio-visuales sumados a varias fotografías sobre lo realizado en Buenos Aires pueden compararse con la acción trasladada a otras estaciones de tren pertenecientes a otras ciudades del mundo. Al respecto, Lola Arias recuerda que en una de las estaciones intervenidas: 
[...] un borracho empezó a gritar contra las pantallas diciendo que esto era la dictadura de la literatura, mientras un grupo de adolescentes llamaba por teléfono a sus amigos para decir 'vení, en la estación están escribiendo sobre mí', y dejaban ir los trenes para quedarse leyendo. Todos esos hechos dan vida a las obras y hacen que la ciudad no sea sólo una escenografía pintada, sino una realidad compleja, con múltiples e incontrolables sentidos (Pitrola, 2010-2011, $\mathrm{s} / \mathrm{p})$.

En definitiva, si bien las estaciones de tren de las diferentes ciudades presentaron varias similitudes (y volvemos a la idea de no-lugar), en cada intervención habría rasgos particulares que se singularizaron, proveyendo datos acerca de cada ciudad intervenida. Desde los hábitos ciudadanos (por ejemplo, el uso del mate), hasta las vestimentas o la época estacional del año atravesada, cada ciudad visible sobre la escena narrada también resulta fluctuante y abierta, como la ciudad real. Ambas ciudades, la real y la narrada, se constituyen a partir de pequeñas historias de sus protagonistas que, a su vez, se disimulan en la homogeneidad del ritmo cotidiano dando lugar a una mirada acostumbrada, distraída. Al proponer modificar esa mirada, particularizando, fragmentando, la intervención de Pensotti logró cuestionar y problematizar ese espacio, autorreferencial como contexto. Entonces, se podría decir que el estar o no en escena durante la intervención ha sido algo fluctuante momento a momento.

\section{El día que dejó de ser uno más, para pasar a ser uno}

Los lugares vividos son como presencias de ausencias (Michel De Certeau, 2007, p. 121)

¿Y si la ciudad fuera también una imagen "[...] capaz de contener la memoria de todo lo que no pudo ser o de aquello que desapareció" (Ballent, 1993, p. 83)? Lo que nos interesa resaltar en este último apartado del trabajo es la idea de una ciudad compuesta no sólo por los hábitos cotidianos, sino también por aquellas fisuras propuestas por las coaliciones urbanas. Es decir, un signo no sólo constituido por lo material y lo acostumbrado en el orden transitado a diario, sino también por aquello que deja sus huellas a nivel perceptivo, como podría ocurrir al retornar a la estación de Palermo una vez acontecida la intervención. Sería también pensar en ese para alguien del que habla Peirce como parte de la acción sígnica, de la decodificación y de la lectura. 
Según Aldo Rossi, la ciudad no sólo es "[...] un objeto material, sino que también es su memoria, que adquiere nuevamente la forma de objetos, aunque de otro tipo: aquellos imaginarios o los que sólo habitan en el recuerdo" (apud Ballent, 1993, p. 83). Este concepto nos permite pensar en la relación entre lo que vemos y lo que pudimos ver, entre las presencias y las ausencias que interactúan a la hora de percibir la arquitectura urbana que nos rodea.

Al reflexionar sobre $A$ veces creo que te veo aparece una ciudad real que se proyecta dentro de una obra y que constituye con ello una analogía de sí misma, lo que daría por resultado una ciudad otra (nueva), para quien quiera participar de ella. Entonces aparece "[...] la impresión de muchas ciudades que se superponen [...] [en] el vínculo con la experiencia" (Agrest, 1998, p. 35), como un punto capaz de entrelazar la arquitectura de la ciudad con su percepción, es decir, un puente entre la ciudad y su cultura. Esto no sería más que proponer una "[...] interrogación ficcional sobre la verdad de la ciudad" (Gorelik, 1998, p. 88). Esto permitiría atender a: "[...] las simbolizaciones culturales que produce la ciudad y que la producen y, de ese modo, trabajar directamente sobre ellas, romper su naturalización [...] produciendo un extrańamiento y una distancia capaz de poner en acto el carácter artificial, cultural por ende, de las figuraciones urbanas" (Gorelik, 1998, p. 92).

Al romper con la naturalización de las formas cotidianas de una simple espera de tren, al disolver con ello el anonimato propio de la multitud, al crear cuerpos definidos dentro de un relato ficcional, la estación ya no siguió siendo la misma. Su resemantización como escenario habilitó nuevos sentidos. De esta manera, la posibilidad de intervención, de fluctuación y de coalición - que también presenta la ciudad sobre su orden estable o esperable - hace que su significado, en términos de Peirce, nunca sea acabado, ya que, como signo, resultaría abierto, no definitivo, es decir "pasible de modificación por la experiencia histórica de la lectura" (Mancuso, 2010, p. 130). La estación de tren Palermo reúne semántica e históricamente la intervención acontecida que hizo de ella un espacio, un texto para la escritura e invención de una trama narradora de pensamientos, de pequeñas historias de la vida cotidiana. Pero con ello no sólo se resignificó el lugar, sino que los sujetos se volvieron parte de esa escritura conjunta, es decir, ellos también pasaron a ser signos escénicos de dicha trama. 
En este trabajo nos interesaba pensar cómo los hábitos rutinarios, al ser suspendidos por los extraordinarios, plantean otras lecturas sobre el espacio urbano y cómo, por lo menos momentáneamente, el sentido naturalizado de ese espacio se podía alterar. Dicho esto, ¿se podría pensar que la intervención de Pensotti dejó una huella sensorial y perceptual capaz de ser recuperada por quienes conocieron la experiencia al volver a dicho lugar? Tal como definió Simmel "si el individuo-mercancía tiende a adormecer ese shock con una percepción distraída (blasé), la puesta en escena de la misma, al hacerla explícita, permite el distanciamiento crítico de la representación naturalizada" (Gorelik, 1998, p. 92). La puesta en escena construida por Pensotti proporcionó, de algún modo, la desnaturalización del escenario cotidiano a partir de lo cual la percepción de ese lugar habría cambiado posteriormente. Mirar y volver a mirar el mismo lugar. Entrar y salir de esa ficción, momentáneamente.

En definitiva, no sabemos donde quedaron las huellas de aquellas presencias ficcionales convertidas en relato, ni si la acción pudo haber resultado relevante o no para quienes participaron como performers o espectadores. Tal vez el haberse convertido en un personaje creado por un escritor sí haya quedado como recuerdo de una experiencia extracotidiana. Sin embargo, de lo que sí podemos dar cuenta es que se trató de un suceso capaz de delinear cuerpos, ya no como uno más dentro de la multitud, sino simplemente como uno, uno en particular. Y esto también es parte de la fluctuación que presenta toda ciudad. 


\section{Notas}

${ }^{1}$ Festival realizado en la ciudad de Buenos Aires y en otras ciudades tales como: Berlín, Varsovia y Zúrich. Compuesto por ocho intervenciones de espacios públicos, semi-públicos y privados - un shopping; una estación de tren; una habitación de un hotel; una fábrica y un departamento; entre otros -, el evento propone formas de accionar sobre la ciudad, descomponiendo la mirada acostumbrada y creando nuevos relatos y sentidos sobre ese espacio utilizado como escenario.

${ }^{2}$ Intervención que continúa siendo representada en diferentes ciudades del mundo hasta la actualidad bajo su traducción: Sometimes I think I can see you.

${ }^{3}$ Disponible en: <http: /www.marioanopensotti.com/avecescreo.html>.

${ }^{4}$ Disponible en: <http: /www.marioanopensotti.com/avecescreo.html>.

5 Disponible en: <http: /www.marioanopensotti.com/avecescreo.html>.

${ }^{6}$ Disponible en: <http: /www.marioanopensotti.com/avecescreo.html>.

\section{Referencias}

AGREST, Diana. Para Aldo, con cariño de una argentina. Revista Block, Buenos Aires, n. 3, p. 32-41, 1998.

AUGÉ, Marc. Los No-lugares: espacios del anonimato. Barcelona: Gedisa, 2005.

BALLENT, Anahí; DAGUERRE, Mercedes; SILVESTRE, Graciela. Cultura y Proyecto Urbano: la ciudad moderna. Buenos Aires: CEAL, 1993.

BOURDIEU, Pierre. Campo de Poder, Campo Intelectual. Buenos Aires: Montressor, 2002 .

BOURRIAUD, Nicolás. Estética Relacional. Buenos Aires: Adriana Hidalgo, 2008.

BUCK-MORSS, Susan. Dialéctica de la Mirada: Walter Benjamin y el proyecto de los Pasajes. Madrid: Visor, 2001.

DE CERTEAU, Michel. La Invención de lo Cotidiano: 1. Artes del hacer. México: Universidad Iberoamericana, 2007.

DELGADO, Manuel. Sociedades Movedizas: pasos hacia una antropología de las calles. Barcelona: Anagrama, 2007.

DERRIDA, Jacques. Espectros de Marx. Madrid: Editorial Trotta, 1995.

DIÉGUEZ CABALLERO, Ileana. Escenarios Liminales: teatralidades, performances y política. Buenos Aires: Atuel, 2007.

DUHAU, Emilio; GIGLIA, Ángela. Espacio público y nuevas centralidades: dimensión local y urbanidad en las colonias populares de la ciudad de México. Papeles de Población, México, Universidad Autónoma Metropolitana, n. 41, jul./sep. 2004.

GORELIK, Adrián. Correspondencias: la ciudad análoga como puente entre ciudad y 
cultura. Revista Block, Buenos Aires, n. 3, p. 88-97, 1998.

JOSEPH, Isaac. El Transeúnte y el Espacio Urbano. Barcelona: Gedisa, 1988.

MANCUSO, Hugo R. De lo Decible. Buenos Aires: Editorial SB, 2010.

MUNTADAS, Antony. Muntadas/Bs.As. Buenos Aires: Espacio Fundación Telefónica, 2007.

PENSOTTI, Mariano. A veces creo que te veo, Buenos Aires, nov. 2010. Disponible en: <http://www.marianopensotti.com/avecescreo.html>. Acceso en: 03 jan. 2013.

PITROLA, Marcelo. Lola Arias y Stefan Kaegi. La ciudad: los usos teatrales. Otra Parte - Revista de Letras y Artes, Buenos Aires, n. 22, s/p, 2010-2011. Disponible en: <http:// www.revistaotraparte.com/n\%C2\%BA-22-verano-2010-2011/lola-arias-y-stefan-kaegi-laciudad-usos-teatrales>. Acceso en: 03 jan. 2013.

SENNETT, Richard. La ciudad abierta. Otra Parte - Revista de Letras y Artes, Buenos Aires, n. 11, s/p, 2007.

María Laura González es investigadora, docente y crítica teatral. Doctora por la Universidad de Buenos Aires, Facultad de Filosofía y Letras en Historia y Teoría de las Artes. Licenciada en Artes (orientación Combinadas) y Profesora en Enseñanza Media y Superior en Artes (FFyL-UBA). Egresada de la carrera Formación Integral del Actor de la Escuela Metropolitana de Arte Dramático (EMAD). Becaria del Consejo Nacional de Investigaciones Científicas y Técnicas (2008-2013). Actualmente es Profesora de Análisis y Crítica del Hecho teatral en la carrera de Artes de la UBA. Se dedica al estudio de performances realizadas en espacios públicos. Desde 2009 integra el staff de la Revista teatral Funámbulos. Y además se desempeña dentro del campo artístico en calidad de actriz.

E-mail: malalitagonzalez@hotmail.com 